LBL-37217

UC-426

6th International Conference on Ion Sources

ICIS'95

September 10-16, 1995

Whistler, B.C., Canada

\title{
High Ion Charge States in a High-Current, Short-Pulse, Vacuum Arc Ion Source
}

Andre Anders, Ian Brown; Robert MacGill, and Michael Dickinson

Lawrence Berkeley National Laboratory, University of California, Berkeley, CA 94720

September 1995

* This work was supported by the Director, Office of Basic Energy Sciences, Advanced Energy Projects Division of the U.S. Department of Energy under Contract No. DEAC03-76SF00098.

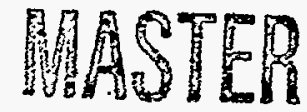




\section{DISCLAIMER}

This report was prepared as an account of work sponsored by an agency of the United States Government. Neither the United States Government nor any agency thereof, nor any of their employees, make any warranty, express or implied, or assumes any legal liability or responsibility for the accuracy, completeness, or usefulness of any information, apparatus, product, or process disclosed, or represents that its use would not infringe privately owned rights. Reference herein to any specific commercial product, process, or service by trade name, trademark, manufacturer, or otherwise does not necessarily constitute or imply its endorsement, recommendation, or favoring by the United States Government or any agency thereof. The views and opinions of authors expressed herein do not necessarily state or reflect those of the United States Government or any agency thereof. 


\section{DISCLAIMER}

Portions of this document may be illegible in electronic image products. Images are produced from the best available original document. 
High Ion Charge States in a High-Current, Short-Pulse,

Vacuum Arc Ion Source

André Anders, Ian Brown, Robert MacGill, and Michael Dickinson

Lawrence Berkeley National Laboratory, University of California, Berkeley, CA 94720

\begin{abstract}
Ions of the cathode material are formed at vacuum arc cathode spots and extracted by a grid system. The ion charge states (typically 1-4) depend on the cathode material and only little on the discharge current as long as the current is low. Here we report on experiments with short pulses (several $\mu \mathrm{s}$ ) and high currents (several $\mathrm{kA}$ ); this regime of operation is thus approaching a more vacuum spark-like regime. Mean ion charge states of up to 6.2 for tungsten and 3.7 for titanium have been measured, with the corresponding maximum charge states of up to $8+$ and $6+$, respectively. The results are discussed in terms of Saha calculations and freezing of the charge state distribution.
\end{abstract}

\title{
I. Introduction
}

Broad beams of multiply charged metal ions can be produced by vacuum arc plasma sources. They have been described in detail in $[1,2]$, and we give here only a brief description. An arc between metal electrodes in vacuum is usually initiated by applying a positive high voltage pulse to a trigger electrode. The arc burns in the plasma formed at non-stationary cathode spots. The cathodic plasma expands from the cathode spots into the vacuum and reaches the ion extractor system which is usually a three-grid system of the acceleration-deceleration type. It is common that ion sources of this type operate in a repetitively pulsed mode (arc duration of order $1 \mathrm{~ms}$ or less) with repetition rates of a few pulses per second, an arc current of 100-300 A, an ion beam current of order $100 \mathrm{~mA}$ (during pulses), and an extractor voltage in the range $20-100 \mathrm{kV}$. The ion charge state 
distribution (CSD) was investigated in a number of papers [1-4], and the most recent table is given in Ref. [1] for 50 cathode materials.

CSDs were found to be fairly reproducible in different embodiments of the vacuum arc ion source. However, it turned out that the CSDs do not only depend on the cathode material but also on the time elapsed since the arc pulse was started [5, 6], and on the presence and strength of an external magnetic field [6-9].

In the present paper we investigate the influence of the discharge current on the CSD. This is motivated by the fact that very high ion charge states have been observed spectroscopically in short-pulse, high-current vacuum spark experiments $[10,11]$. High charge states are of interest for obtaining high ion energies at a given extractor voltage.

\section{Experiments}

For our experiments we used a vacuum arc ion source similar to what has been described previously $[1,12]$. The arc was fed by a 7 -stage LC-pulse line of $1.5 \Omega$ impedance, resulting in pulses of 100-300 A amplitude, $5 \mu$ s rise time and $250 \mu$ s duration. The cathode spots burned on the front face of a water-cooled, cylindrical cathode of 6.2 $\mathrm{mm}$ diameter, the annular anode had an inner diameter of $20 \mathrm{~mm}$ and was $1 \mathrm{~cm}$ apart from the cathode surface (Fig. 1). The anode hole diameter was reduced to $4 \mathrm{~mm}$ or $2 \mathrm{~mm}$ for discharge currents higher than $300 \mathrm{~A}$ and $3 \mathrm{kA}$, respectively, in order to avoid breakdown of the extractor voltage. The plasma leaving the arc discharge region expanded while streaming towards the extractor grids. The extractor grids had holes of $6 \mathrm{~mm}$ diameter and were placed $10 \mathrm{~cm}$ downstream the anode. The ion beam had a diameter of about $10 \mathrm{~cm}$.

To achieve higher currents and shorter pulses, the LC pulse forming network was replaced by a fast high voltage capacitor ( $\mathrm{C}=12 \mu \mathrm{F}$ or $100 \mu \mathrm{F}$ in different experiments). The arc current was controlled by using various inductive loads $(0.1-10 \mu \mathrm{H})$ and a $100 \mathrm{~m} \Omega$ Ohmic resistor. In most experiments, the capacitor was located very close to the electrode arrangement to keep the circuit inductance relatively small (about $0.1 \mu \mathrm{H}$ ), and thus pulsed 
currents of several kiloamperes could be obtained even with the charging voltage not exceeding $600 \mathrm{~V}$. The arc pulse length was in the range of 3-25 $\mu$ s (FWHM). Ions of charge state $z$ are accelerated to the energy $E_{z}=z U_{\text {extr }}$; the default extractor voltage was $U_{\text {extr }}=50 \mathrm{kV}$. Titanium and tungsten were used as cathode materials. The CSD was investigated by a time-of-flight (TOF) charge-to-mass spectrometer described elsewhere [12].

\section{Results}

Fig. 2(a) shows a typical TOF spectrum for Ti obtained by the "standard" low-current vacuum arc ion source. The arc current was $150 \mathrm{~A}$, and the mean ion charge state was $\bar{z}=2.2$, measured $100 \mu$ s after triggering. As a first step towards higher currents and shorter pulses we used a $100 \mu \mathrm{F}$ capacitor and a circuit inductance of $3.6 \mu \mathrm{H}$. The titanium CSD at a peak current of $560 \mathrm{~A}$ (30 $\mu$ s after triggering) is shown in Fig. 2(b); $\bar{z}=2.4$ that is only slightly higher than at "standard" operation.

Higher discharge currents were achieved by reducing the inductive load. Figure 2(c) shows the titanium CSD at $1.8 \mathrm{kA}$ peak current $(12 \mu \mathrm{F}$ capacitor, the FWHM of the current pulse was $6 \mu$ s) with $\bar{z}=3.6$, i.e. significantly higher than at "standard" operation, and $\bar{z}=3.75$ has been obtained at $3.4 \mathrm{kA}$.

It is known from previous work [3] that cathode materials of high boiling point tend to have high charge states; the empirical law $\bar{z}=0.38\left(T_{b p}\left({ }^{\circ} \mathrm{C}\right) / 1000\right)+1$ was derived for discharge currents smaller than $200 \mathrm{~A}$. To proof this rule at higher currents we replaced the titanium cathode $\left(T_{b p}=3287^{\circ} \mathrm{C}\right)$ by a tungsten cathode $\left(T_{b p}=5660^{\circ} \mathrm{C}\right)$. The mean ion charge state at "standard" operation (150 A, $100 \mu$ s after triggering) is $\bar{z}=3.1$. Figs. 3(a) and (b) show TOF spectra of tungsten ion beams obtained with $12 \mu$ s pulses at a peak current of $3.4 \mathrm{kA}$ with $\bar{z}=5.8$ and 6.3 . There is obviously a considerable shot-to-shot variation in the CSD but a clear increase of $\bar{z}$ with current (Fig. 4). 


\section{Discussion}

The formation of ions at cathode spots is associated with phase transitions and ionization of the cathode material. Although a number of papers have been published [1319], a satisfying model has not yet been formulated. It has been shown that inhomogeneous heating of the cathode surface (mainly by ion bombardment) leads to local melting and the formation of a dense, non-ideal plasma of micron-size. This is the plasma of "microspots" which expands rapidly, driven mainly by the pressure gradient to the vacuum ambient. While local thermodynamic equilibrium is established close to the spot (within a distance of order $100 \mu \mathrm{m}$ from the spot center), the expanding plasma quickly goes into non-equilibrium at low density.

As long as equilibrium conditions are fulfilled (the time between inelastic collisions is short compared to the characteristic expansion time), the plasma composition can be calculated by a set of Saha equations $[15,17,19,20]$. Figs. 5-8 show calculated plasma compositions assuming a plasma temperature of $3 \mathrm{eV}$ and $5 \mathrm{eV}$ for titanium and $4 \mathrm{eV}$ and 6 $\mathrm{eV}$ for tungsten. For these calculations, ionization energies and partition functions have been taken from Refs. [21-23]. For the lowering of the ionization energies we used the Debye-Hückel model which is valid for weakly non-ideal plasmas. The calculation for tungsten are somewhat uncertain since we used self-consistent-field Hartree-Fock results for the ionization energies [21] and estimates for the partition functions (to our knowledge, no experimental data are ávailable).

When ionizing/recombining collisions become infrequent the composition of the plasma "freezes". Although "freezing" is actually a step-wise process [15], it is reasonable to look for a combination of plasma density and temperature which approximately gives the experimentally observed CSD. In this way, we determined a "freezing temperature" and "freezing density" as indicated in Figs. 5-8.

At low current, plasma is produced at a single cathode spot or very few spots. The plasma of each spot can expand independently from the plasma of other spots, and the 
plasma density decreases as $r^{-2}$ where $r$ is the distance from the spot center. Freezing typically occurs at a density of heavy particles $n_{h} \approx 10^{25} \mathrm{~m}^{-3}$ ([17] and Figs. 5, 6).

At high current, the freezing process and the resulting CSDs are changed by two effects. First, more energy is invested in each heavy particle. If we assume that (i) the : amount of plasma produced is proportional to the current and (ii) the plasma conductivity does not change significantly with increasing current, then the energy per particle is approximately proportional to the current. Therefore, the plasma temperature increases with current. Second, many spots are simultaneously active at high current, and the plasma of each spot expands under the influence of neighboring plasmas. Thus the expansion is not as rapid as in the previous case, and the density drops as $r^{-v}$ with $v<2$. The characteristic expansion time becomes longer, and freezing occurs at lower densities and larger distances from the cathode. These effects are illustrated in Figs. 7 and 8.

New effects must be expected at much higher currents (many $\mathrm{kA}$ ). Erosion of material occurs not only from the cathode but also from the anode. Compression and plasma heating by the self-magnetic field leads to much higher charge states in "hot spots" within the plasma $[10,12]$. More effort will be needed these effects for the formation of beams of even higher charged metal ions.

\section{Acknowledgments}

We would like to acknowledge the generous help of Thomas Schülke, Germany, in performing the numerical calculations. This work was supported by the U.S. Department of Energy, Division of Advanced Energy Projects, under contract No. DE-AC0376 SF00098. 


\section{References}

[1] I. G. Brown, Rev. Sci. Instrum. 65, 3081 (1994).

[2] I. G. Brown, in The Physics and Technology of Ion Sources, edited by I. G. Brown (Wiley, New York, 1989), p.331.

[3] I. G. Brown and X. Godechot, IEEE Trans. Plasma Sci. PS-19, 713 (1991).

[4] I. G. Brown, B. Feinberg, and J. E. Galvin, J. Appl. Phys. 63, 4889 (1988).

[5] J. E. Galvin, I. G. Brown, and R. A. MacGill, Rev. Sci. Instrum. 61, 583 (1990).

[6] A. Anders, S. Anders, B. Jüttner, and I. G. Brown, IEEE Trans. Plasma Sci. PS21, 305 (1993).

[7] E. M. Oks, I. G. Brown, M. R. Dickinson, R. A. MacGill, H. Emig, P. Spätke, and B. H. Wolf, Appl. Phys. Lett. 67, 200 (1995).

[8] E. M. Oks, I. G. Brown, M. R. Dickinson, R. A. MacGill, this Conf. (6th ICIS, Whistler, Canada, 1995), to be published in Rev. Sci. Instrum.

[9] F. J. Paoloni and I. G. Brown, Rev. Sci. Instrum. 66, 3855 (1995).

[10] R. Beier and H.J. Kunze, Z. Physik A 285, 347 (1978).

[11] C. R. Negus and N. J. Peacock, J. Phys. D: Appl. Phys. 12, 91 (1979).

[12] I. G. Brown, J. E. Galvin, R. A. MacGill, and R. T. Wright, Rev. Sci. Instrum. 58,1589 (1987).

[13] S. Anders, Contrib. Plasma Phys. 26, 416 (1986).

[14] C. Wieckert, Contrib. Plasma Phys. 27, 309, (1987).

[15] S. Anders, A. Anders, J. Phys. D: Appl. Phys. 21, 213, (1988).

[16] N. Radic and B. Santic, Proc. XIII Int. Symp. Discharges and Electrical Insulation in Vacuum (Paris), edited by J. M. Buzzi and A. Septier, 217, 1988.

[17] S. Anders, A. Anders, Contrib. Plasma Phys. 29, 537, (1989).

[18] N. B. Volkov and A. Z. Nemirovsky, J. Phys. D: Appl. Phys. 24, 693, (1991).

[19] A. Anders, S. Anders, A. Förster, and I. G. Brown, Plasma Sources Sci. Technol. 1, 263, (1992). 
[20] E. M. Oks, A. Anders, I. G. Brown, M. R. Dickinson, R. A. MacGill, submitted to IEEE Trans. Plasma Sci.

[21] T. A. Carlson, C. W. Nestor, N. Wasserman, and J. D. McDowell, Atomic Data 2, 63, (1970).

[22] S. Bashkin and J. O. Stoner, Atomic Energy-Level and Grotrian Diagrams, vol. II, Sulfur I - Titanium XXII, (North-Holland Publ. Comp., Amsterdam, 1978).

[23] H.-W. Drawin and P. Felenbok, Data for Plasmas in Local Thermodynamic Equilibrium, (Gauthier-Villars, Paris, 1965).' 


\section{Caption of Figures}

Fig. 1 Schematic of the source of multiply stripped metal ions and TOF diagnostics (not to scale).

Fig. 2 TOF spectra of titanium ion beams: (a) "standard" ion source, $150 \mathrm{~A}, 100 \mu \mathrm{s}$ after triggering; (b) $30 \mu \mathrm{s}$ after triggering, using a $100 \mu \mathrm{F}$ capacitor, $560 \mathrm{~A}, 60 \mu \mathrm{s}$ pulse; (c) $3 \mu$ s after triggering, $12 \mu \mathrm{F}$ capacitor, $1.8 \mathrm{kA}$; $6 \mu$ s pulse.

Fig. 3 TOF spectra of tungsten ion beams: (a) $6 \mu$ s after triggering, $100 \mu \mathrm{F}$ capacitor, 3.4 $\mathrm{kA} ; 12 \mu \mathrm{s}$ pulse; (b) same as (a) showing the large shot-by-shot variation.

Fig. 4 Increase of the mean ion charge state with discharge current. Each point represents an average of 16 discharges.

Fig. 5 Composition of a Ti plasma in equilibrium at $3 \mathrm{eV}$ (Saha calculation); the freezing in the case of low current is indicated.

Fig. 6 As Fig. 5 but for tungsten at $4 \mathrm{eV}$.

Fig. 7 Composition of a Ti plasma in equilibrium at $5 \mathrm{eV}$; the freezing in the case of high current is indicated.

Fig. 8 As Fig. 7 but for tungsten at $6 \mathrm{eV}$. 


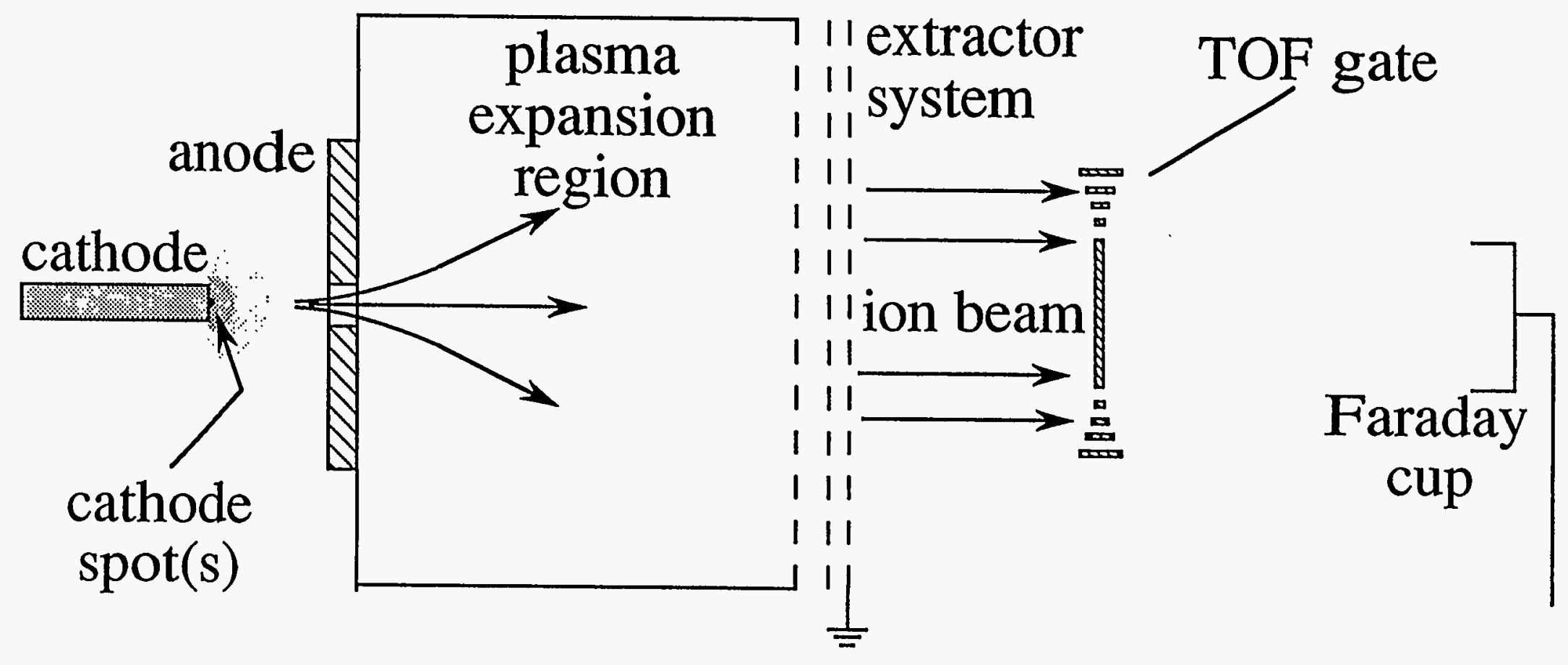

Figure 1 


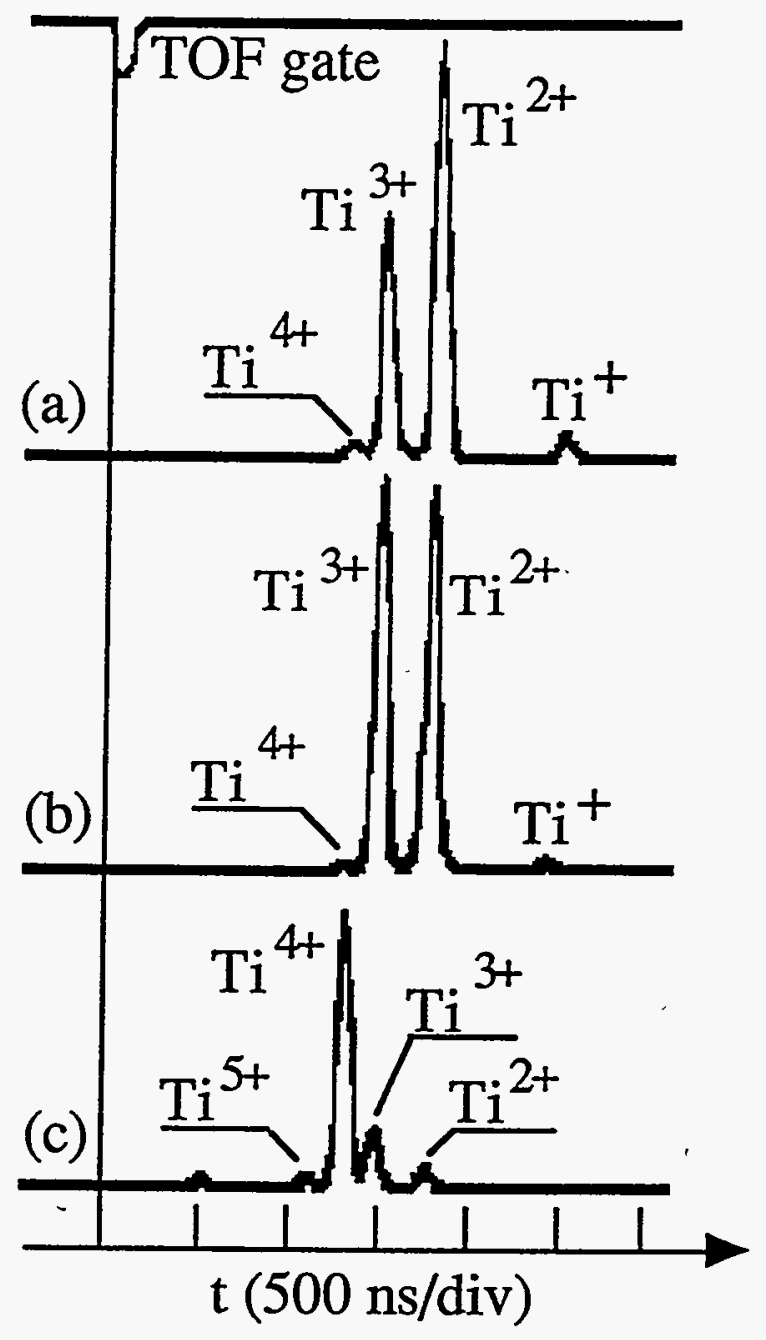

Figure 2 


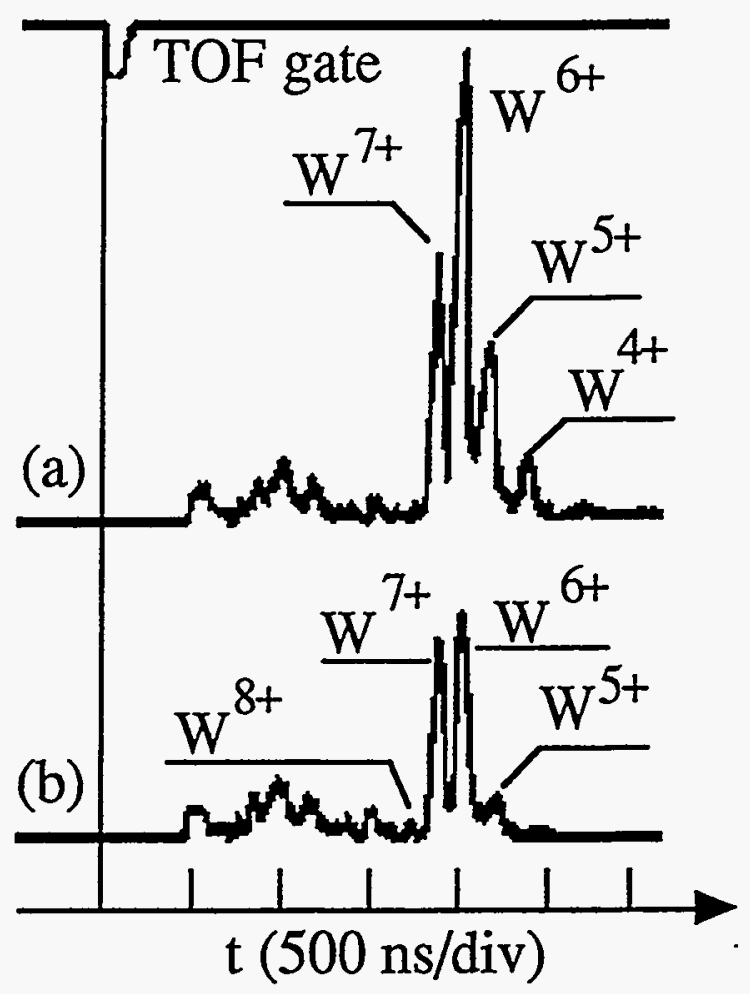

Figure 3 


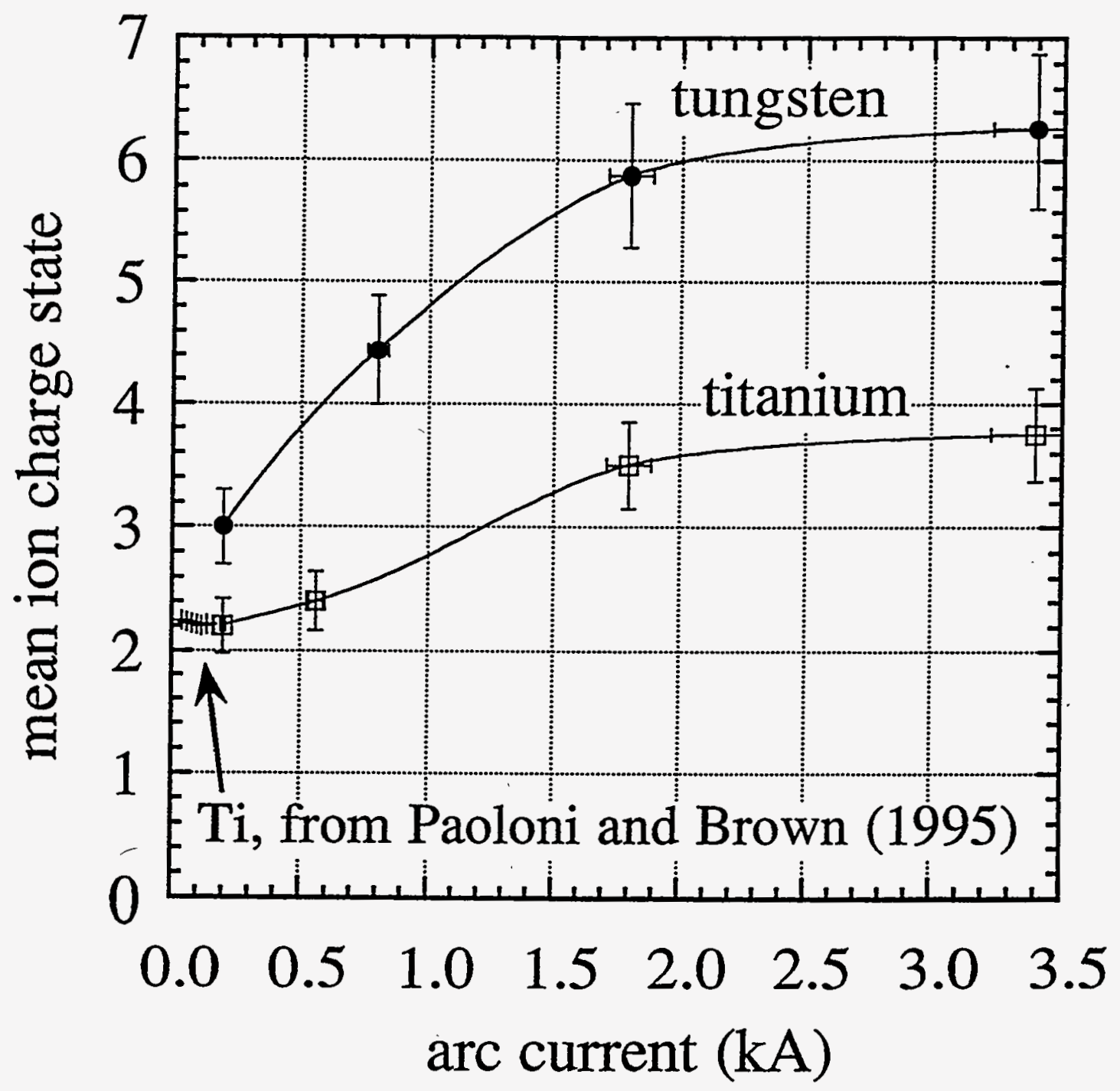

Fig. 4 


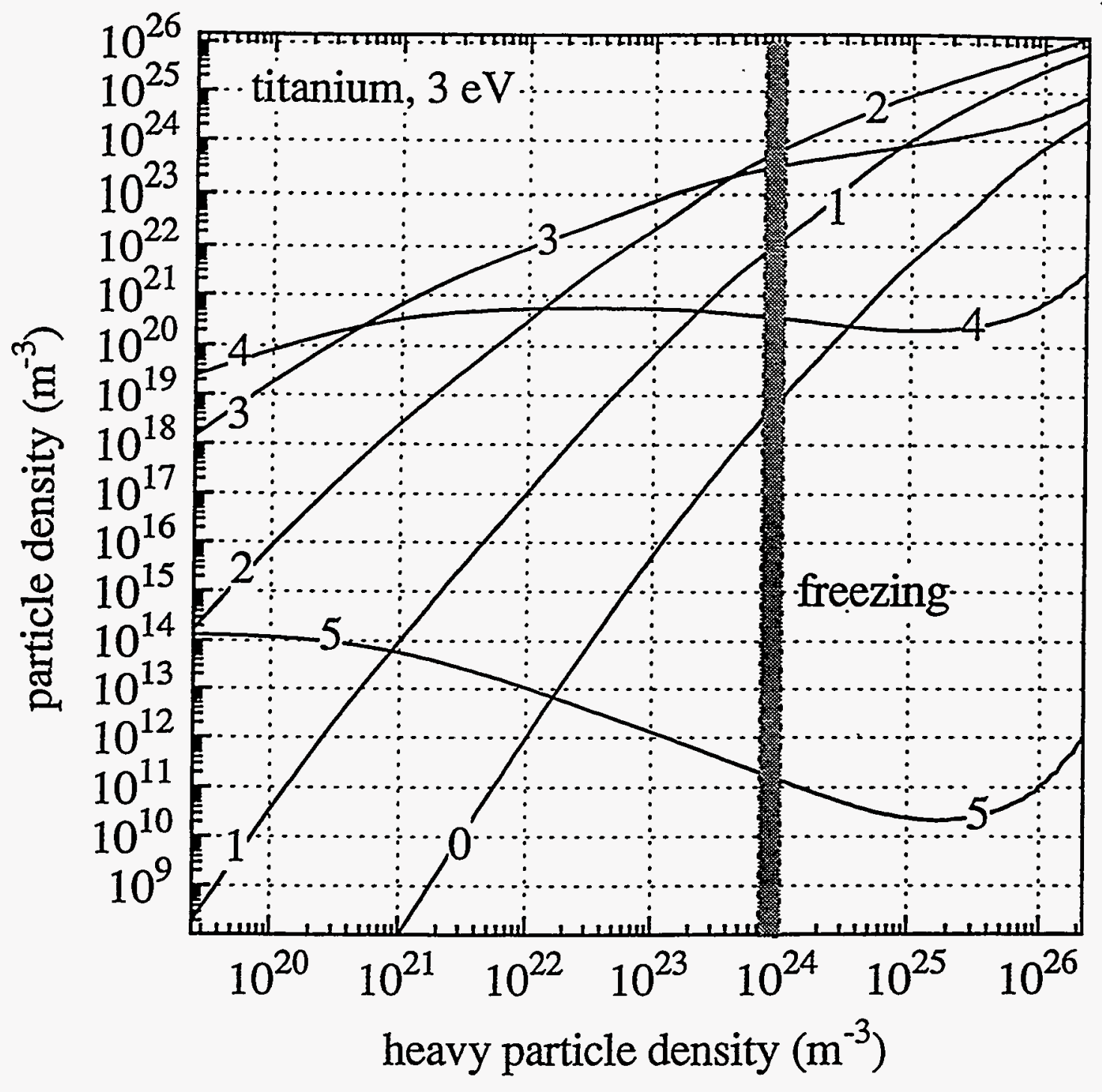

Fig. 5 


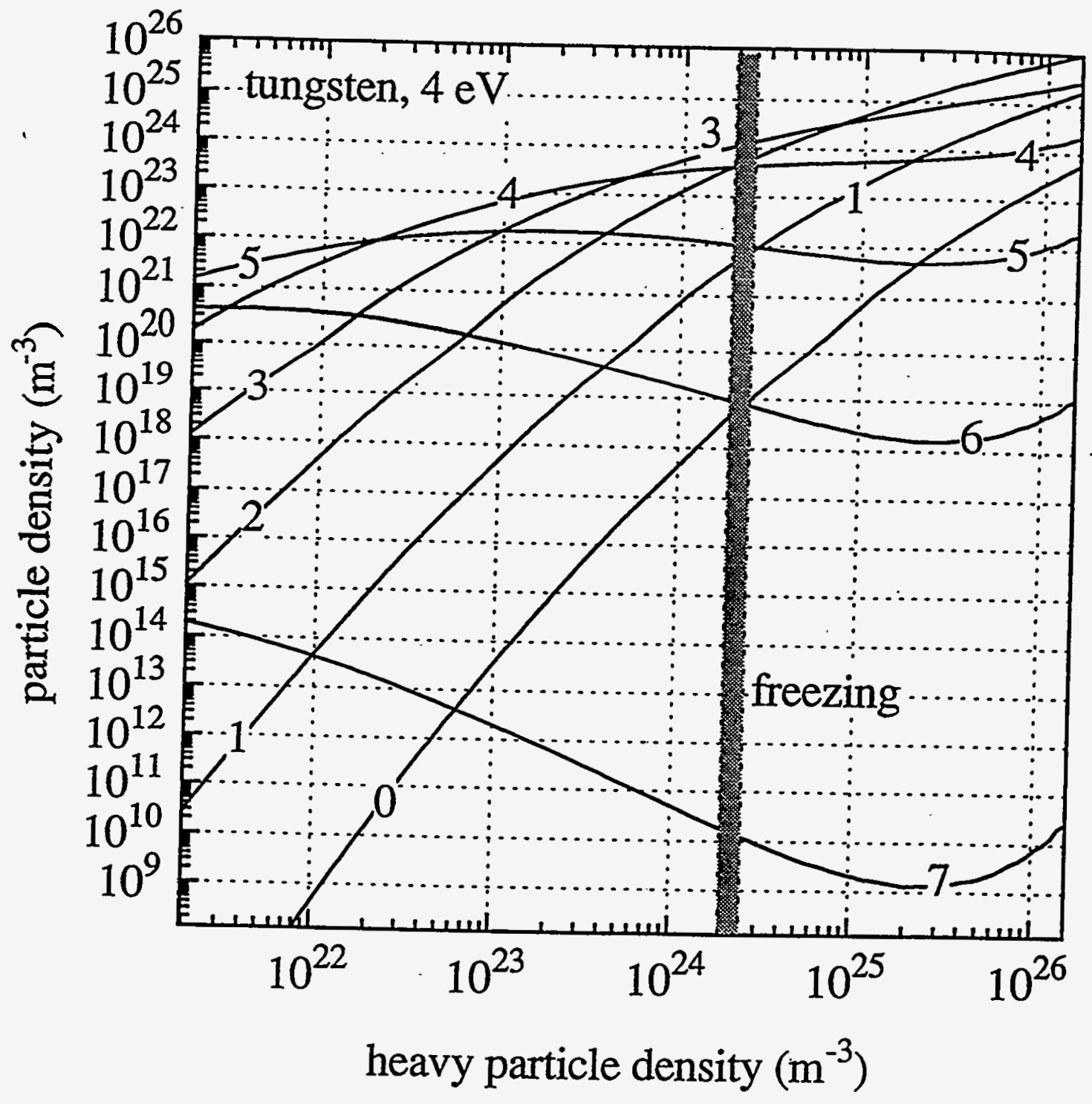

Fig. 6 


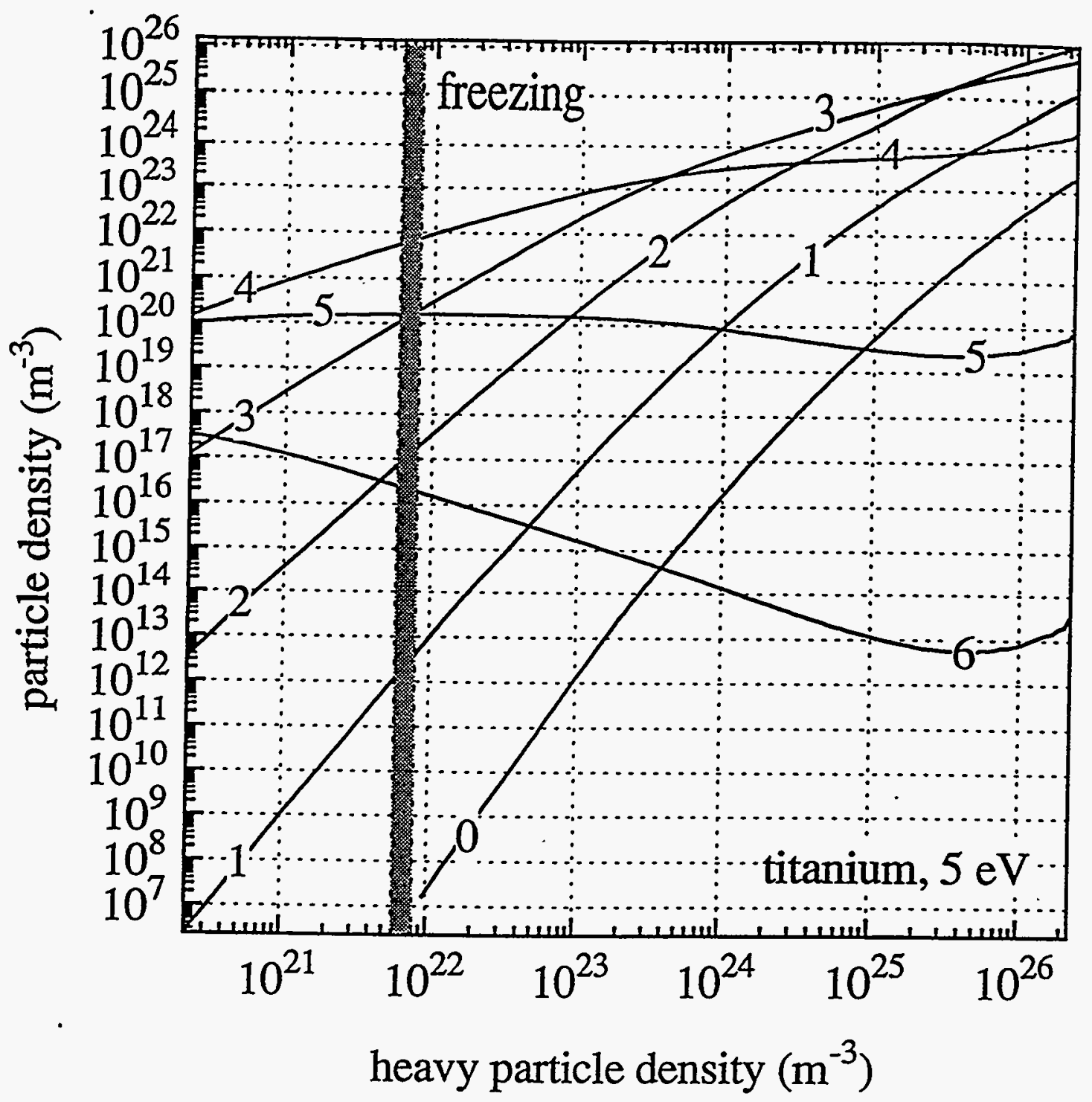

Fig. 7 


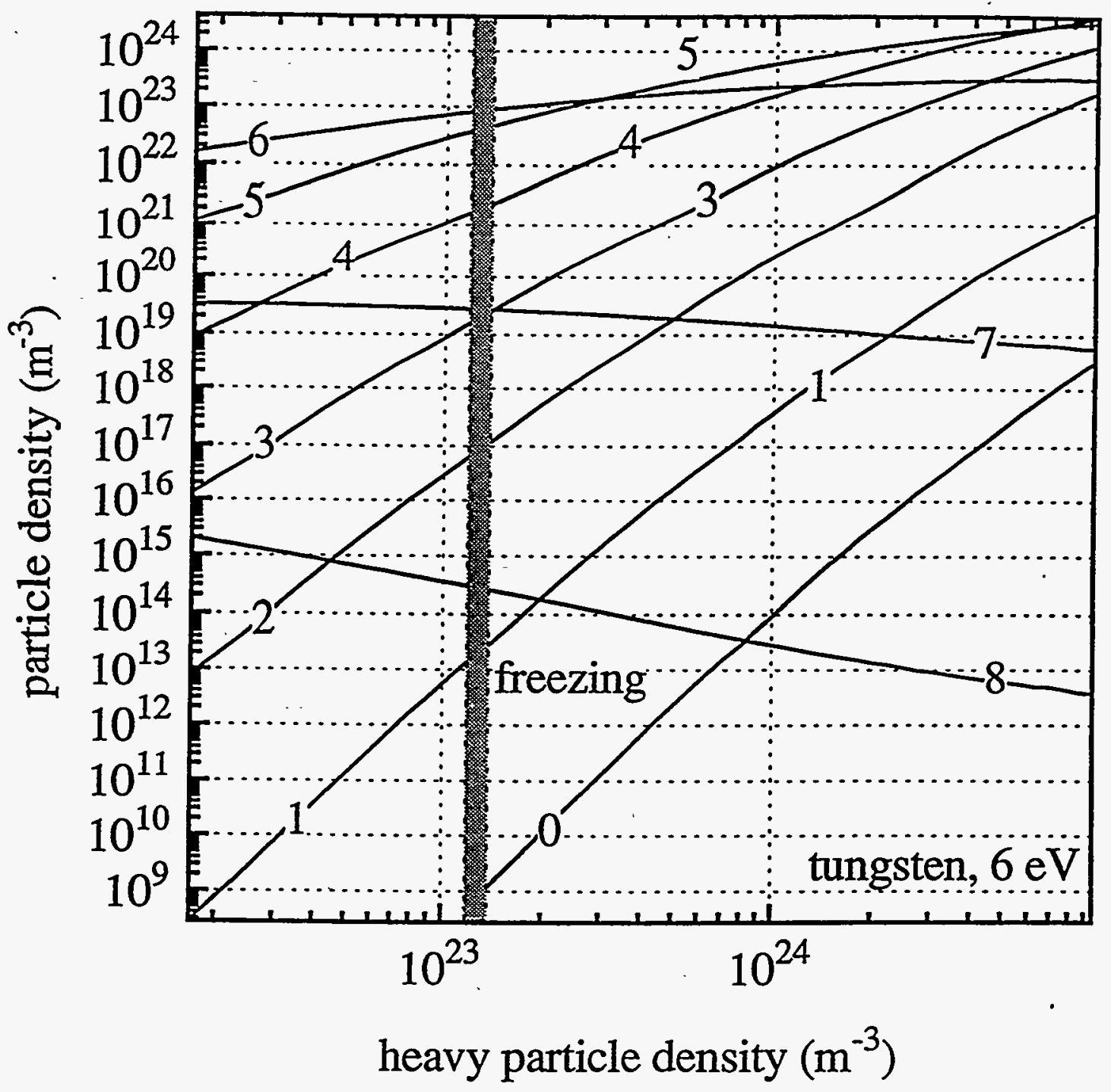

Fig. 8 